University of Wollongong

Research Online

Faculty of Business - Papers (Archive)

Faculty of Business and Law

$1-1-2015$

Household distributional and revenue recycling effects of the carbon price in Australia

Disna Sajeewani

University of Wollongong

Mahinda Siriwardana

University of New England

Judith Mcneill

University of New England

Follow this and additional works at: https://ro.uow.edu.au/buspapers

Part of the Business Commons

Research Online is the open access institutional repository for the University of Wollongong. For further information contact the UOW Library: research-pubs@uow.edu.au 


\title{
Household distributional and revenue recycling effects of the carbon price in Australia
}

\begin{abstract}
The Australian Government introduced a carbon tax from 1 July 2012. The then opposition party leader, now Prime Minister, introduced legislation to repeal the tax. Amongst the many issues being debated is that of the incidence of the tax. In this study, we explore household consumption and income changes arising from a A\$23 carbon price employing a computable general equilibrium model (entitled A3E-G). The model has been calibrated using a social accounting matrix database of Australia with 10 household income groups. This carbon price generates A\$6.39 billion revenue while reducing Australia's carbon emissions by $11 \%$. The empirical evidence suggests household level impacts range from proportional to mildly progressive tax incidence. In this study, we propose four revenue recycling options to overcome any undesirable distributional effects from the carbon price. Results indicate that revenue recycling through income tax reductions and uniform lump sum transfers improves post tax income levels and welfare towards middle and high income groups. A nonuniform lump sum transferring option favors low income households. Uniform reductions in commodity tax rates are not found to be welfare improving but we find positive impacts on export competitiveness from this option.
\end{abstract}

\section{Keywords}

australia, revenue, price, distributional, household, carbon, effects, recycling

\section{Disciplines}

Business

\section{Publication Details}

Sajeewani, D., Siriwardana, M. \& Mcneill, J. (2015). Household distributional and revenue recycling effects of the carbon price in Australia. Climate Change Economics, 6 (3), 1550012-1-1550012-23. 
Climate Change Economics, Vol. 6, No. 3 (2015) 1550012 (23 pages)

(C) World Scientific Publishing Company

DOI: $10.1142 / \mathrm{S} 2010007815500128$

\title{
HOUSEHOLD DISTRIBUTIONAL AND REVENUE RECYCLING EFFECTS OF THE CARBON PRICE IN AUSTRALIA
}

\author{
DISNA SAJEEWANI \\ School of Economics, University of Wollongong \\ Wollongong 2522, Australia \\ disna@uow.edu.au \\ MAHINDA SIRIWARDANA* \\ UNE Business School, University of New England \\ Armidale 2351, Australia \\ asiriwar@une.edu.au \\ JUDITH MCNEILL \\ Institute for Rural Futures, BCSS \\ University of New England \\ Armidale 2351, Australia \\ jmcneill@une.edu.au \\ Accepted 12 May 2015 \\ Published 8 July 2015
}

The Australian Government introduced a carbon tax from 1 July 2012. The then opposition party leader, now Prime Minister, introduced legislation to repeal the tax. Amongst the many issues being debated is that of the incidence of the tax. In this study, we explore household consumption and income changes arising from a $\mathrm{A} \$ 23$ carbon price employing a computable general equilibrium model (entitled A3E-G). The model has been calibrated using a social accounting matrix database of Australia with 10 household income groups. This carbon price generates A $\$ 6.39$ billion revenue while reducing Australia's carbon emissions by $11 \%$. The empirical evidence suggests household level impacts range from proportional to mildly progressive tax incidence. In this study, we propose four revenue recycling options to overcome any undesirable distributional effects from the carbon price. Results indicate that revenue recycling through income tax reductions and uniform lump sum transfers improves post tax income levels and welfare towards middle and high income groups. A nonuniform lump sum transferring option favors low income households. Uniform reductions in commodity tax rates are not found to be welfare improving but we find positive impacts on export competitiveness from this option.

Keywords: Australia; general equilibrium model; carbon price; household; revenue recycling.

JEL Codes: D58, D62, Q52, Q58

${ }^{*}$ Corresponding author. 


\section{Introduction}

Greenhouse gas mitigation policy is one of the most contentious political issues in the Australia history. Although now repealed, at the time of this research, the previous Australian government had implemented a carbon tax with the intention of transforming it into an emissions trading scheme on 1 July 2015. During this period the Australian Treasury undertook extensive economic modeling using three top-down computable general equilibrium (CGE) models namely, global trade and environment model (GTEM), G-cubed model and the Monash multi-regional forecasting (MMRF) model, to simulate various emission reduction scenarios in which Australia and the world follow pathways to a low pollution future (Australian Government, 2008). The projections at sector specific and household distributional levels were obtained by integrating with a series of bottom-up sector specific models of electricity, transport, land use change and forestry, and household micro simulation models. However, these integrated household micro simulation models are partial equilibrium models and are not best suited to analyze public policies that give rise to economy wide distributional effects. As such, carbon price impacts that give rise to distributional consequences are not adequately captured through relative price changes in Australia. More specifically, these household micro simulation models do not account for the interaction of the general equilibrium effects in the economy resulting from a policy change.

It is apparent that carbon tax creates general equilibrium effects in the economy. The most effective tool for analyzing such market interaction effects on households is a CGE model. For instance, once the determinants of demand and supply of every market and the cross linkages are specified, a CGE model then recalculates a 'new' equilibrium set of prices after a policy shock. This is the ability of CGE models to simultaneously determine changes in the quantities of goods supplied and demanded and their prices. As a result, a CGE model is capable of finding solutions in an aggregated multi-sectoral and multi-agent setup.

A CGE model can be calibrated with an Input-Output (IO) database or a Social Accounting matrix (SAM) database. All the CGE models employed in Australia for carbon price simulations have been calibrated with IO databases with an aggregate household sector representing the consumers in the economy. Then a micro simulation model has supplemented the disaggregated household level details. Those micro simulation models have only captured the flows of goods between industries and final consumers and they do not explain income flows between these institutions. An alternative way of obtaining the distributional consequences of carbon price policy is to calibrate a CGE model with a SAM database with a disaggregated household sector. For instance, a CGE model calibrated with a conventional IO table only captures sectoral interdependence in a detailed production account whereas a SAM-based model elaborates and articulates the generation of income by activities of production and the distribution and redistribution of income between social and institutional groups (Round, 2003). Fulfilling this important research gap in Australia, we propose 
to employ a CGE calibrated with a disaggregated SAM database to quantify the distributional impacts of the carbon price policy in Australia and also proposes various options by which households can be compensated in order to reduce the tax burden created on them.

The paper is organized into six sections. Section 2 provides a brief overview of literature employing CGE models to estimate household distributional effects and revenue recycling effects of carbon tax policy. Section 3 sets out the methodological approach with a description of model structure and the database used in the household sector modeling. Section 4 presents carbon tax policy simulations with regard to household distributional effects and revenue recycling effects. Sensitivity analysis of the model is presented in Sec. 5. Finally, Sec. 6 provides concluding remarks for this study.

\section{Literature Review}

Various studies have been undertaken in Australia by employing CGE models to assess the economic and sectoral impacts of climate change mitigation policies. Most of these studies have employed the ORANI model developed by Dixon et al. (1977). Deviating from the well-known Johansen class multi-sectoral models, ORANI allows for one industry to produce more than one commodity, an appropriate definition for modeling Australian agriculture. Due to the flexibility in the reclassifying of variables between the exogenous and endogenous categories, ORANI showed potential for use in analyzing various alternative policy scenarios. McDougall (1993a) produced short-run costs of Australia's greenhouse gas abatement by employing an enhanced version of the ORANI multi-sectoral model (Adams and Dixon, 1992). This version of ORANI contained a detailed fossil fuel use structure. A carbon tax of A $\$ 19$ per tonne is applied to domestic fuel usage which excludes exports and domestic nonfuel use. The results show that the carbon tax raises output prices, especially prices of energy intensive commodities.

Based on Dixon et al. (1982), Powel and Snape (1993) employed ORANI-E which contains several energy specific enhancements embedded into the database as well as into the theoretical structure of the model. This version of ORANI-E is used to simulate the long-run effects of an energy tax which is levied on consumption of fossil fuels (McDougall, 1993b). The main simulation represents the introduction of the energy tax while two alternative energy related taxes are introduced for comparison namely a carbon tax and a tax on petroleum products. The results show that both the carbon and energy tax reduce carbon emissions and fossil fuel energy consumption.

The development of MMRF-Green (Adams et al., 2000a) model which is a dynamic, multi-sectoral, multi-regional CGE model with detailed environmental specifications of the Australian economy can be seen as another milestone of Australian greenhouse gas mitigation policy modeling. The environmental capabilities of the model include an energy and gas emissions accounting module, equations describing 
inter-fuel substitution in electricity generating by regions, and mechanisms for the endogenous take-up of abatement measures in response to greenhouse policy measures. The MMRF-Green model is used to simulate the effects of a domestic capand-trade permit system with auctioned permits to meet Kyoto Protocol commitments (Adams et al., 2000b).

Other CGE models namely GTEM and G-cubed are also used as tools for climate change policy modeling in Australia. Since both these models are global CGE models, Australia is represented as one of the regions in the model structure. The GTEM has evolved from the MEGABARE model developed by ABARE (1996) and the static GTAP model (Hertal, 1997). MEGABARE is a dynamic CGE model of the world economy which was developed to address climate change policy issues.

The Australian Treasury used a suite of three top-down CGE models namely GTEM, G-Cubed and MMRF to analyze climate change mitigation policies in Australia. While MMRF is a detailed model of the Australian economy with state and territory level detail, the two other models are global models with Australia represented as one of the regions. Several bottom-up sector specific models of electricity generating, road transport, agriculture and forestry sectors and household distribution complement the macro results drawn from these CGE models. Details on the modeling framework and results are included in the Treasury modeling reports (Australian Government, 2008, 2011a). Most notably, until the Treasury incorporated some of the recommendations of the Clean Energy Future policy package - the policy package that foreshadowed the introduction of the carbon tax - to model distributional consequences of carbon tax revenue recycling impacts (Australian Government, 2011b), there has been very little detailed research conducted in Australia to model revenue recycling effects of a carbon tax.

Revenue recycling of carbon tax revenue offers the potential to offset undesired negative implications of imposition of the tax. A regulatory tax usually creates inefficiency in the economy, however, Pigou (1932) proposed a tax on polluters to offset their underestimated input prices as a mean of correcting market inefficiencies created by negative externalities. The uses of such Pigouvian taxes to internalize the external costs were identified as having double dividends - the reduction of pollution together with the imposition of a corrected social cost (Tullock, 1967).

Generally speaking, the double dividend hypothesis in environmental taxation promotes the recycling of revenues from environmental taxes to reduce other distortions in the tax system. In the first dividend, an environmental tax contracts demand for the polluting agent which reduces associated pollution. The second dividend is achieved if the revenue is recycled back to the economy to reduce other forms of distortionary taxes. For instance, a regular tax creates welfare losses while a pollution tax creates welfare gains after correcting for an externality (see for example, Baumal and Oates (1988); Lee and Misiolek (1986)). Early surveys of the double dividend hypothesis can be found in Bosello et al. (2001), Bovenberg (1995), Bovenberg and Goulder (1998, 1999) and Schob (1997). 
Many studies have been undertaken to identify this important implication arising from the double dividend form of a carbon tax. In this case, various other distortionary taxes are used to swap with the revenue gained from carbon tax; most notably to reduce taxes on the factor labor (e.g., income tax), value added tax, or corporate tax (Mathur and Morris, 2014; Metcalf, 2007, 2013; Carbone et al., 2013; Marron and Toder, 2013; Parry, 1997; Standaert, 1992; Barker et al., 1993). However, carbon tax revenue is also widely used in ex post lump-sum redistribution to the population (Zhang and Baranzini, 2004). This is mainly because if a carbon tax generates regressive impacts, the lowest income groups can proportionately receive higher amounts of government transfers than the higher income households and this could therefore be used as an acceptable fiscal policy measure to mitigate regressive impacts of carbon tax policy.

For instance, Bor and Huang (2010) classified supplementary measures to improve the efficiency of energy taxation into two categories: green tax reform and fiscal policy. Using an ORANI- recursive dynamic CGE model, they simulated the effects of various supplementary scenarios on industrial structure and on different economic factors such as economic growth, the price level, employment, tax revenue, and $\mathrm{CO}_{2}$ emissions. This study confirms the use of green tax reform measures such as reducing individual income tax and business income tax as the best options to achieve double dividend effects. However, energy tax combined with fiscal measures such as subsidizing public transport and investment on research and development can give rise to reduced energy consumption, thereby re-enforcing the first dividend - i.e., $\mathrm{CO}_{2}$ emissions control.

Labandeira et al. (2004) proposed a methodology to explore the double dividend arising from environmental taxes. They employed a static, energy-focussed CGE model of a small open economy with four energy commodities (coal, oil, gas, and electricity) in the production factor specification. The $\mathrm{CO}_{2}$ emissions data were obtained for each sector. With the introduction of a carbon tax, sectors with high carbon emissions contracted (for example electricity, transport, and chemicals). When the carbon tax is revenue neutral (i.e., the tax revenue is used to cut labor taxes), the most immediate effects are seen on the reduced marginal wage rate paid by employers and increased labor demand. The social welfare gain, measured as equivalent variation (EV) in real terms, experiences a 256 million Euro increase which provides an environmental improvement (first dividend) of 221 million Euro and a fiscal improvement (second dividend) of 35 million Euro.

McKitrick (1997) considered five revenue recycling policies namely lump-sum transfer to households, goods and services tax reduction, corporate income tax reduction, personal income tax reduction, and payroll tax reduction to implement a double dividend case of the carbon tax in Canada. A static CGE model is used to assess carbon emission control policies by calculating coefficients which relate fuel use to $\mathrm{CO}_{2}$ release. Other than fuel, certain manufacturing industries such as ammonia and cement production are also considered as major emitters of $\mathrm{CO}_{2}$. The carbon tax 
rate is determined endogenously in order to achieve a $12.5 \%$ emissions reduction against the base year 2000. Results indicate that the carbon tax revenue recycled through lump-sum transfer to households, GST reduction and corporate income tax reduction scenarios are not welfare improving. However, the case of a carbon tax recycled through payroll tax reductions and personal income tax reductions do generate welfare improvement. The McKitrick study gives a broader theoretical insight for analyses of double dividend environmental taxation under alternative revenue recycling options.

Another important implication of carbon tax policy is the associated distributional effects within a country that implements it. This is mainly because distributional impacts are different between developed and developing countries. The majority of studies carried out in developed countries show that a carbon tax policy is regressive, while developing country studies indicate that a carbon tax policy is not necessarily regressive and, in some instances, can be progressive. Hamilton and Cameron (1994) employed a hypothetical carbon tax simulation model for Canada, including a CGE model, a cost-push model, a detailed energy disposition account, and a microsimulation model of household expenditures. The CGE model suggests a carbon tax of US $\$ 101.56$ per tonne of carbon is the most efficient policy. The cost-push model and a detailed energy disposition account are then used to simulate the direct and indirect effects of a carbon tax on domestic prices, particularly prices paid by final consumers. These price changes are applied to individuals, families, and households in a microsimulation model. According to the cost-push model, the study reveals that consumer expenditure is most significantly affected by the tax. Furthermore, the microsimulation model reveals that the distributional consequences of the carbon tax are moderately regressive.

In contrast to the regressive view of a carbon tax policy, Yusuf and Resosudarmo (2007) suspected that such a policy may actually have progressive impacts on households due to changes in factor prices or levels of employment after a policy change. They employed a general equilibrium model with some modifications to the standard ORANI-G model in order to investigate the distributional impacts of a carbon tax on Indonesian households. This model incorporated substitution possibilities of energy commodities, a $\mathrm{CO}_{2}$ emission accounting framework, and multiple household income and expenditure accounts. The model is calibrated using a SAM with disaggregated households for the year 2003. In their simulation strategy, carbon tax revenue (US\$32 per tonne of $\mathrm{CO}_{2}$ ) is recycled through uniform cuts on commodity tax and uniform income transfer options. These simulation results suggest that the uniform tax cut is expansionary for all commodities, as far as macroeconomic impacts or aggregate welfare is concerned. The distributional impacts of the carbon tax are progressive in rural areas whereas in the urban areas impacts largely depend on how the revenue from carbon tax is recycled. Overall, the net impact nationwide is progressive under all scenarios. Therefore, this study encourages developing countries to reduce 
their carbon emissions as it is possible for them to benefit from desirable distributional implications while contributing to the global carbon mitigation action.

Similarly, Oladosu and Rose (2007) found a carbon tax was progressive in terms of the distribution of personal income. By employing a static, regional CGE model with four types of economic activities (production, consumption, trade and investment) the authors simulated the aggregate, sectoral, consumption and income distribution impacts of a carbon tax policy. With regard to income distribution impacts, short-run results are more favorable towards the first four income classes. The last five income groups suffered most. The only exception is the decrease in demand for fuel/utilities and transportation across all income groups. Measures of welfare impacts on a carbon tax show a relatively improved outlook for lower income households in terms of percentage change in the per capita income. Furthermore, the Gini coefficient declined by around $0.15 \%$ in the short and long term, indicating that the carbon tax is mildly progressive.

Furthermore, Labandeira et al. (2009) proposed an integrated methodology to provide a thorough analysis of the efficiency and distributional effects of energy tax reform in Spain employing a CGE model and a microeconomic model. The microeconomic demand model is capable of providing distributional effects associated with the tax reform, while the CGE model provides efficiency effects of those policies. Using this methodology they find household impacts are moderately progressive with the tax reform. Basically, the foundation for distributional outcomes has arisen from the heterogeneity of price effects among goods and services and between households.

Basically, research suggests that the distributional implications of a carbon tax is a very important factor to consider. If low-income households are made worse-off by the carbon tax, there is a need to compensate them by a tax cut (from pre-existing taxes) or lump-sum re-distribution of income. Usually, lump-sum redistribution of carbon tax revenue does not deliver double dividends or efficiency gains as compared to cuts in other forms of existing distortionary taxes. However, in some cases most distortionary taxes fall on high income groups and as such, revenue recycling may increase welfare towards high income groups raising concerns about equity issues. In this sense, Zhang and Baranzini (2004) and Dinan and Rogers (2002) suggest the unavoidable need to make a trade-off between efficiency and equity in the use of carbon tax revenues in order to make a tax distributionally neutral or even progressive impact.

\section{Methodological Approach}

The CGE model (entitled A3E-G) used in this study is based on the ORANI-G model which is an applied general equilibrium model of the Australian economy (Horridge, 2000). In the model, the production function in each sector is modeled under a nested Leontief or constant returns to scale production technology. The assumptions of a 
classical CGE approach are profit maximization of the producers and utility maximization of the consumers. The interactions with each agent bring markets into equilibrium where prices are competitively determined. By including a carbon price, the A3E-G model recalculates equilibrium prices and quantities of factors and commodities. This is based on the assumption that a price on carbon will influence the decision-making processes of both producers and consumers.

Key characteristics embedded in the A3E-G model which deviate significantly from the standard ORANI-G model are: first, the A3E-G model treats nonenergy commodities and energy commodities separately (see similar type modeling structures in Devarajan et al., 2009, 2011; Telli et al., 2008; Yusuf and Resosudarmo, 2007). Energy commodities are categorized into coal, oil, gas, petroleum and commercial electricity. The commercial electricity generation mix is composed of coal, oil, gas and renewable sources. Second, the model allows price-induced substitution between capital and energy and between different energy commodities.

Third, a carbon emission accounting and carbon price mechanism incorporated into the model allows solving for another equilibrium state after a carbon price shock. $\mathrm{CO}_{2}$ emissions are made proportional to the energy inputs (except for commercial electricity) used and/or to the level of economic activity. In the model, carbon emission intensities are computed from stationary fuel combustion. These emission intensities are assumed fixed in the model to reflect unchanged technology and household preferences. Therefore, once the carbon price is introduced, the model re-calculates the market equilibrium based on emissions intensities associated within each sector. Since there are no separate carbon emissions accounts data for imported commodities, the study assumes carbon emissions are only associated with domestic commodities and processes.

Finally, the A3E-G model contains equations explaining both the income and expenditure sides of the household, corporations, government and the rest of the world accounts. Due to space limitations this paper presents detailed information on the household sector of the model only. The model includes 10 household groups based on the income deciles. Each household demand system follows a linear expenditure system (LES). Therefore, household demands for commodity composites (domesticimported) are aggregated by a Klein-Rubin function (Klein and Rubin, 1948-49). At the next bottom level (as shown in Fig. 1) the domestic and imported commodity composite is modeled using the Armington aggregation. The representative household in each group is assumed to be choosing commodity $c$ from source $s$ to minimize the cost of achieving the optimal levels of composite commodity subject to a nested CES utility function.

The solution to this optimization problem determines the domestic-import composite of household demand. At the top level household demand for composite commodities are derived by maximizing a Klein-Rubin utility function subjected to a household budget constraint. The household income is sourced from supply of labor (different occupational groups), rent from capital and income transfers from households, government, corporations (nonfinancial and financial) and from the ROW. 


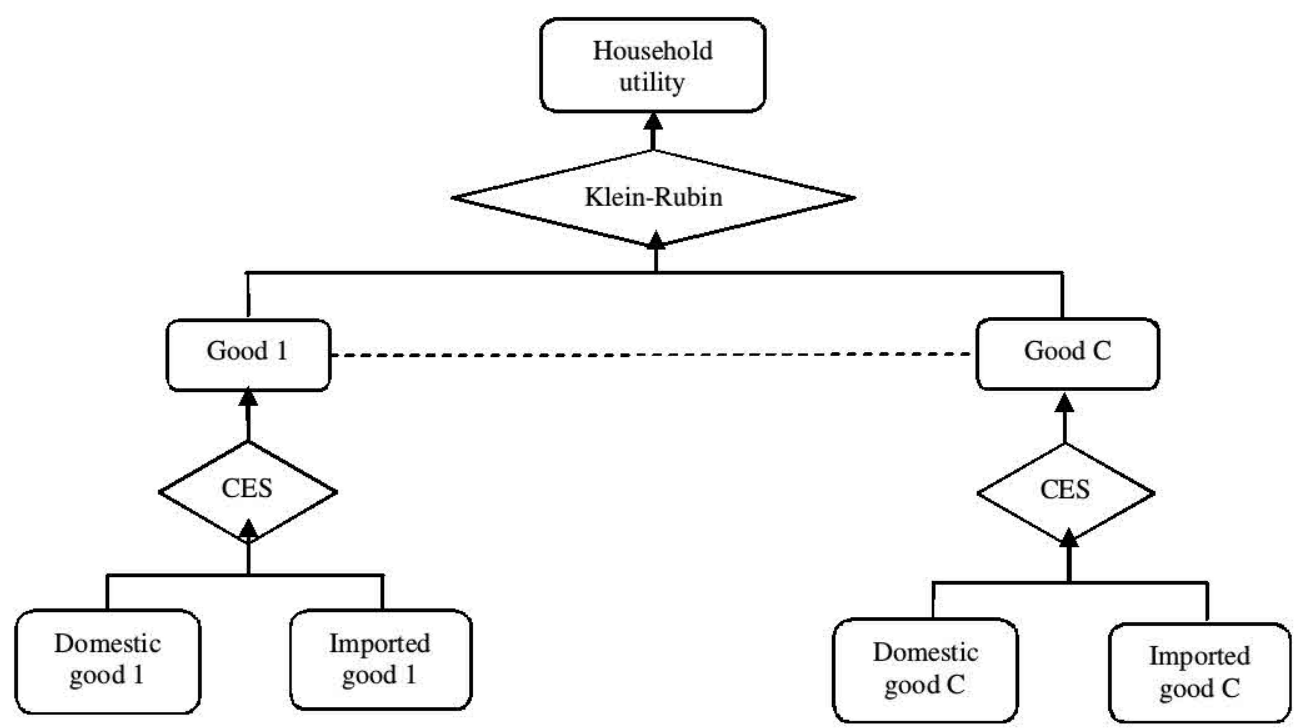

Figure 1. Structure of household demand.

Accordingly, when the carbon price alters the equilibrium allocation of resources, the model can be further used to analyze various carbon tax revenue recycling policies. ${ }^{1}$

\section{Carbon Tax and Revenue Recycling Simulations}

A carbon price raises the prices of energy and emission intensive commodities and as a result household income and consumption will change (these are the distributional consequences). Under these circumstances it is essential for the government to provide adequate and timely assistance to households on low incomes who are particularly vulnerable to cost pressures. In this sense, the Clean Energy Future Act included several measures to support households and indicated that at least half of the carbon revenue was to be distributed to households (Australian Government, 2011c). Further, it was mentioned that this assistance was to be delivered through social security payment increases and tax cuts. Based on this detail in the Act, we implement four alternative revenue recycling options to explore possibilities of improving household welfare.

For all these policy experiments, a base case - A \$23 carbon price (CTX) under the short-run economic environment is used. The short-run assumption fixes the capital stocks and real wages in the factor market. Then the aggregate real private consumption expenditure is declared as endogenous in order to obtain welfare impacts of the carbon price policy. Similar approaches can be found in the studies of Horridge (2000) and Yusuf (2007). The model is solved by declaring an equal number of

\footnotetext{
${ }^{1}$ Due to space limitation equation systems are not presented in this paper and can be obtained by email correspondence with the authors.
} 
Table 1. Alternative carbon tax revenue recycling scenario.

Description

LSO $50 \%$ of the carbon tax revenue is redistributed to all households based on original government transfer ratios. ${ }^{\mathrm{a}}$

LSE $50 \%$ of the carbon tax revenue is redistributed equally among all 10 household income groups.

INC $50 \%$ of the carbon tax revenue is redistributed to reduce payment of income tax by households. ${ }^{b}$

GST $50 \%$ of the carbon tax revenue is returned to the economy by way of reducing Goods and

Services Tax (GST) paid by households. ${ }^{\mathrm{c}}$

\begin{abstract}
${ }^{a}$ The original government transfers are the transfers made by the government to the households and those ratios are computed from the SAM as follows: $17 \%, 29 \%, 17 \%, 19 \%, 4 \%, 5 \%, 3 \%, 3 \%, 1 \%$ and $2 \%$ to decile 1 to 10 , respectively.

${ }^{\mathrm{b}}$ The income tax payment is considered as a household direct payment to government. Therefore, the compensation revenue is used to reduce payments to the government at a rate of $0 \%, 7 \%, 9 \%, 7 \%, 6 \%$, $5 \%, 9 \%, 8 \%, 16 \%$ and $33 \%$ for deciles 1 to 10 , respectively.

${ }^{\mathrm{c}}$ Household payments of GST are in the proportion of $4 \%, 4 \%, 6 \%, 7 \%, 8 \%, 10 \%, 11 \%, 13 \%, 15 \%$ and $21 \%$ by deciles 1 to 10 , respectively.
\end{abstract}

endogenous variables with equal number of equations. Finally, the model determines changes in domestic prices induced by the shock as changes in domestic prices relative to world prices. This is achieved by fixing the nominal exchange rate as the numeraire.

Table 1 details four recycling policy options to reduce some of the burden on the household sector resulting from the introduction of a carbon price in the economy. ${ }^{2}$ Under these scenarios, only half of the revenue will be recycled. The remainder is used to run a budget surplus. These options are compared with CTX, in which case all the revenue collected will be used to run a budget surplus, thus, fully exogenizing the government budget deficit/surplus variable.

\title{
4.1. Macroeconomic impacts
}

Table 2 presents the impacts of $\mathrm{A} \$ 23$ carbon price on important macroeconomic variables. The carbon price has reduced the real GDP relative to the baseline by $0.60 \%$. This is because the carbon price is implemented as a form of a tax which distorts economic efficiency. Since the GDP measure can be taken from both supply and demand side components, the carbon price may have caused impacts on both sides. On the supply side, a carbon price increases the cost of variable factors of production which in turn reduces the incentive for producers to employ these factors in their production processes. This is seen as an increase of cost of labor in the short-run. Since nominal wages are indexed to the consumer price index, the increase in the consumer price index by $0.71 \%$ will lead to a proportional increase in nominal wages. This creates a wedge between the price of spending and the average price of output in the

\footnotetext{
${ }^{2}$ Although labor tax reduction is another popular option under the double dividend hypothesis, it is not simulated due to short-run assumption of the model. In order to implement this option it is necessary to have defined an endogenous labor supply equation.
} 
Table 2. Percentage change impacts of a $A \$ 23$ carbon price on macroeconomic variables.

\begin{tabular}{lr}
\hline Macro variable & Short-run \\
\hline Real GDP & -0.60 \\
Aggregate employment & -0.87 \\
Real household consumption & -0.17 \\
Export volume index & -2.76 \\
Consumer price index & 0.71 \\
Real devaluation & -0.73 \\
Terms of trade & 0.29 \\
Price of electricity & 23.79 \\
Emissions reductions $(\mathrm{Mt})$ & 70.13 \\
Emissions reduction $(\%)$ & -11.94 \\
Carbon tax revenue $(\$$ billions) & 6.39 \\
\hline
\end{tabular}

Source: A3E-G model projections.

economy (Adams, 2007). This can be observed as a rise in wages relative to the price of output leading to an increase in the real cost of labor.

The demand side components of the GDP are also affected. This is seen in the reduction in household consumption by $-0.17 \%$ and export volume by $-2.76 \%$. Household real consumption has been affected mainly because of changes in real income available for consumption. The results show that the aggregate demand for employment decreased by $-0.87 \%$ which is the main source of household income (i.e., there has been a reduction in wages). Furthermore, the domestic currency has appreciated against the foreign currency by $0.73 \%$ in real terms, which may have further induced the reduction in exports. As a result, Australia's competitiveness in the international market has been affected by the carbon price.

The proposed carbon price decreased emissions by $11.94 \%$ ( 70.13 million metric tonnes of $\mathrm{CO}_{2}$-e). Because we calculated emissions coefficients of stationary fuel (energy commodities), the sector level results reveal intensities of emissions reduction in which those sectors use different proportions of energy in their production processes. Accordingly, high carbon emitting energy related industries namely, brown coal, black coal, oil and petroleum sectors and energy intensive industries namely, iron and steel, aluminium have reported significant contractions in emissions and output. The electricity price increment under the policy is projected to be $24 \%$. This result is not surprising as a significant proportion of Australia's electricity is generated by emissions intensive brown coal and black coal sources The total revenue generated under this carbon price is A $\$ 6.39$ billion.

\subsection{Household income distribution and consumption impacts}

The social accounting data used in this model provides detailed information regarding household income patterns and expenditure sources. Household income is determined 
as changes in wage income (disaggregated into nine occupational groups), capital rent, land rent, government transfers and other transfers. Wage income is received mainly by the households and comprises the major part of household income.

A carbon price changes the composition of household consumption of goods and services in the economy. The increased prices of carbon intensive commodities will have a disproportionate impact on those households which consume more carbon intensive commodities. For instance, commodities that are required for subsistence requirements are purchased regardless of their price increase. The remaining consumption - the 'luxury' or 'supernumerary' expenditure - is altered with relative price changes. Table 3 shows the percentage change in household real consumption and real income under the $\mathrm{A} \$ 23$ carbon price. The real household consumption of each income group is negatively related and it is quite clear that in the short run it generates proportionate consumption reductions in the income groups of deciles 3 to 10 . With respect to changes in patterns of energy consumption, low income households may be more vulnerable to the carbon price as compared to high income groups. For instance, the first two income groups (deciles 1 and 2) experience very slight reductions in their real consumption. This could be due mainly to consumption of subsistence commodities being a major part of their consumption. Generally, low income households proportionately spend more on energy-intensive commodities, mainly electricity. In contrast, rich households can adjust to the relative price shifts because a larger proportion of their income may be spent on energy-intensive luxury commodities.

Overall, the income distributional impacts range from proportional to mildly progressive tax incidence. There is no significant impact on deciles 1 and 2 . These two groups receive a significant proportion of government transfers which constitute their major source of income. As a result, introduction of a carbon price may not necessarily

Table 3. Projected real consumption and real income effects among household deciles.

\begin{tabular}{lcc}
\hline Household income deciles & Real consumption & Real income \\
\hline 1st & -0.002 & -0.14 \\
2nd & -0.001 & -0.18 \\
3rd & -0.030 & -0.62 \\
4th & -0.051 & -0.55 \\
5th & -0.107 & -0.76 \\
6th & -0.128 & -0.73 \\
7th & -0.162 & -0.75 \\
8th & -0.186 & -0.72 \\
9th & -0.211 & -0.64 \\
10th & -0.328 & -0.68 \\
\hline
\end{tabular}

Note: Projections are in percentage changes from the base solution. Source: A3E-G model projections, 1st-10th range poorest to richest. 
reduce household post tax income. The rest of the income groups share the burden quite proportionately to their relative income, with middle income groups (deciles 5, 6, 7 and 8) fairing the worst. This is because in the short-run, household incomes are mainly affected from the changes in labor supply rather than changes in capital rent. Accordingly, this projection confirms that middle income households receive wage income as a major part of their total income. The post tax income effect on the last two income deciles (deciles 9 and 10) are relatively less than the average middle income group effect. These income groups receive a higher share of capital income relative to wage income. This result partly explains the finding of Rausch et al. (2010) that progressivity of the carbon tax results in when a significant proportion of the carbon price is passed back to the owners of factors of production - mostly to the owners of natural resources and capital.

\subsection{Household revenue recycling}

Table 4 provides key macroeconomic results of the A $\$ 23$ carbon price policy (CTX) along with the four revenue recycling policy experiments. As shown, the projected emissions reductions under all revenue recycling policies are quite similar to that of the CTX policy. Therefore, these recycling policies can be used effectively to improve the welfare of households without disturbing the emissions abatement effort in the economy.

The impact on real GDP has improved under all revenue recycling policies as compared to the CTX policy. Both LSE and GST policies have improved the impact on real GDP by around $60 \%$ compared to the CTX policy. Even though both LSO and LSE policies are lump-sum transfer options, the impact on real GDP is much higher under the LSE policy $(-0.21 \%)$ compared to LSO policy $(-0.53 \%)$. This is mainly due to the fact that energy consumption is a normal good and consumption improves across all household groups under the LSE option. Since, the carbon tax results in a proportional to a mildly progressive tax incidence, the lump-sum transferring across the board (LSE) seems to be improving overall household incomes as compared to the

Table 4. Macroeconomic results of the carbon price revenue recycling experiments.

\begin{tabular}{lrrrrr}
\hline Variable & CTX & LSO & LSE & INC & GST \\
\hline Emissions reduction (\%) & -11.94 & -11.93 & -11.96 & -11.96 & -11.74 \\
Real GDP & -0.60 & -0.53 & -0.21 & -0.54 & -0.29 \\
Real household consumption & -0.17 & 0.88 & 5.26 & 0.76 & -0.05 \\
Export volume & -2.76 & -5.07 & -14.68 & -4.81 & -1.26 \\
Import volume & 0.07 & 0.67 & 3.32 & 0.60 & 0.14 \\
Consumer price index & 0.71 & 1.25 & 3.80 & 1.85 & -0.25 \\
Real devaluation & -0.73 & -1.28 & -3.82 & -1.22 & -0.06 \\
\hline
\end{tabular}

Note: Projections in percentage changes from the base solution.

Source: A3E-G model projections. 
LSO option and shows improvement in the Real GDP ( $-0.21 \%)$. Real GDP improves under the GST policy because the distortionary effect of the tax in the economy has reduced. The reduction in GDP under the LSO and the INC policies is $10 \%$ less than the reduction in GDP under the CTX policy.

The CPI rises significantly under LSO, LSE and INC policies compared to CTX policy. However, under the GST policy the CPI shows a negative growth of $0.25 \%$. As a result, the GST policy improves exports by 54\% compared to the CTX policy. Overall, the GST policy improves the export competitiveness in the economy as compared to other policies. All other revenue recycling policies showed deteriorating export levels. The highest reduction in exports of $14.7 \%$ is seen under the LSE policy. This result is somewhat surprising as compared to other options. However, as observed, imports have significantly increased (3.32\%) under LSE. This could be due to improved ability of households to switch away from high cost domestic commodities towards low cost import substitutes. These interaction effects have given rise to an appreciation of the currency by $3.82 \%$ and a further fall in exports to that extent.

All revenue recycling policies improve aggregate household real consumption by comparison with the CTX policy. However, the reduction in GST fails to generate a noticeable impact on household real consumption which still experiences a negative change of $0.05 \%$. This is because food and exports are GST exempt and households' consumption of energy goods remain unaffected by the GST cut. The largest improvement in the household real consumption can be seen with the LSE policy which increases the aggregate household real consumption by $5.26 \%$. The LSO and INC policies improve the aggregate real household consumption by $0.88 \%$ and $0.76 \%$, respectively.

Under these three policies (LSE, LSO, INC), households have more capacity to alter their decisions toward the consumption patterns that have initially been affected by the carbon price policy. Indeed the INC policy supports the double dividend hypothesis where the carbon revenue reduces distortionary income taxes in the economy. However, LSE option is more welfare improving because it is distributed equitably across all household groups whereas INC option is mostly benefiting higher income groups. Overall, all these revenue recycling options improve household real consumption and increase the welfare gain in the economy without disturbing the carbon emissions abatement policy.

\subsection{Household distribution analysis under various recycling policies}

The household distributional effects under various recycling policies in terms of percentage changes in real income, utility and equivalent variation (EV) are presented in this section. Table 5 shows the percentage changes of household incomes under all revenue recycling policies compared to the CTX policy. As discussed before, under the CTX policy the overall impact ranges from a proportional to a mildly progressive tax incidence with middle income households (deciles 5, 6, 7 and 8) affected the most. 
Table 5. Percentage changes in post tax income by household decile.

\begin{tabular}{lrrrrr}
\hline Household income deciles & CTX & LSO & LSE & INC & GST \\
\hline 1st & -0.14 & 2.40 & 1.32 & -0.14 & -0.05 \\
2nd & -0.18 & 3.06 & 0.91 & 0.55 & -0.07 \\
3rd & -0.62 & 0.89 & 0.29 & 0.21 & -0.23 \\
4th & -0.55 & 0.80 & 0.15 & -0.08 & -0.21 \\
5th & -0.76 & -0.52 & -0.16 & -0.44 & -0.29 \\
6th & -0.73 & -0.48 & -0.17 & -0.45 & -0.27 \\
7th & -0.75 & -0.62 & -0.21 & -0.32 & -0.28 \\
8th & -0.72 & -0.60 & -0.26 & -0.39 & -0.27 \\
9th & -0.64 & -0.59 & -0.18 & -0.09 & -0.23 \\
10th & -0.68 & -0.63 & -0.33 & 0.06 & -0.24 \\
\hline
\end{tabular}

Source: A3E-G model projections; 1st-10th range poorest to richest.

Since a larger proportion of household incomes in deciles 1 and 2 receive government transfers, the LSO policy has significantly increased their post tax income levels compared to the baseline by $2.4 \%$ and $3.1 \%$, respectively. Furthermore, the projected post tax income changes are positive among the deciles 3 and 4 since these groups also receive a significant proportion of their income in the form of government transfers. The rest of the income groups (deciles 5-10) benefited less from the carbon tax revenue transferring based on the original government transfer ratios and their percentage change in income remains negative, although with a slight improvement compared to the CTX policy. Therefore, progressivity of the carbon price policy becomes quite significant under the LSO policy. As such, compensating households under the LSO policy is essentially of political interest in Australia where the targeted population usually comprises those households with lower incomes.

The LSE policy is designed to transfer carbon tax revenue equally among all household groups. Under this policy, percentage changes of the post tax income from deciles 5 to 10 have significantly improved compared to the LSO policy. However, these deciles still experience negative post tax income changes although with a lesser decline than that occurred under the CTX policy. This is mainly because the amount of compensation is not sufficient to fill the gap created as a result of large income losses experienced by these households. In contrast, the amount of revenue received is sufficient to uplift the post tax income levels of the lowest income groups. This is seen as a positive change in the post tax income of the household group from deciles 1 to 4 . There is a progressive effect under this option, although the magnitude of the effect is greater than under the LSO policy.

The percentage change in the post-tax income of decile 1 under the INC policy has not resulted in any impact compared to the CTX policy and remains as $-0.14 \%$. The income tax paid by this group is very small, nearly zero, thus households falling under this income group have not benefited from this policy. Interestingly, the post tax 
income changes in the deciles 2 and 3 have been positive. The rest of the households (deciles 4-9) still register negative percentage changes in the post tax income. Decile 10 registers a positive change in post tax income by $0.06 \%$. This is because this group pays a relatively higher amount of income tax to the government and as a result the group benefits from the INC policy. Overall, the results indicate this compensation policy has brought positive post tax income changes at two ends; the richer (decile 10) and the poorer (deciles 2 and 3). However, the results show improvement in post tax income levels in the middle income groups as compared to the uncompensated CTX policy.

Post tax income changes of the GST policy follow the same pattern to that of the CTX policy. The reduction in GST applies to value added production within each sector without distorting the relative costs of inputs. However, it does distort the composition of output to a small extent. This explains why the GST reduction affects the overall consumption level slightly less than other revenue recycling options. In this policy experiment, the GST cut has proportionately improved the post tax income of households from deciles 3-10 compared to the CTX policy but the impacts are minor as compared to lump-sum transfer options (LSO and LSE). This shows that spending patterns on energy related goods by the Australian households are distributed proportionately to their income. The exceptionally high (low negative values) post tax income changes of households 1 and 2 are due to the fact that these groups receive a larger portion of their income as government transfers. Thus, while their previous posttax incomes remain intact, the GST option further improves their post-tax income levels.

A carbon price affects the consumption pattern of households. As such, the percentage change in household utility can be used as a reliable indicator of welfare. With the given LES consumption function, the change in consumption is largely realized through the change in supernumerary (luxury expenditure) consumption. Therefore, the utility of a given household group measures the likelihood of changing its supernumerary consumption.

The percentage change in utility of the 10 household groups is given in Table 6 . The household utility change is progressive under the CTX policy. Once households are compensated by the LSO policy, the utility change improves towards low income household groups. This is because low income groups get more opportunities to increase their consumption of luxury commodities under this policy as compared to high income groups. However, once an equal dollar amount is given to all households (LSE policy), utility significantly increases towards higher income groups allowing these groups to consume more of the luxury goods. The INC policy has proportionately boosted the consumption level of the luxury commodities by all household groups whereas the GST policy produced less of an impact on household utility compared to the CTX policy. Still, the income groups from deciles 4 to 10 have projected negative percentage changes of utility with the GST policy. Overall, the results indicate that utility can be used as a proxy indicator to see how households respond to consumption 
Table 6. Percentage change in household utility.

\begin{tabular}{lrrrrr}
\hline Household deciles & CTX & LSO & LSE & INC & GST \\
\hline 1st & -0.04 & 6.04 & 3.51 & 2.66 & 0.04 \\
2nd & -0.01 & 6.85 & 2.51 & 3.49 & 0.11 \\
3rd & -0.27 & 4.78 & 3.03 & 3.32 & 0.08 \\
4th & -0.35 & 4.52 & 2.41 & 2.85 & -0.05 \\
5th & -0.59 & 3.12 & 8.35 & 2.45 & -0.16 \\
6th & -0.59 & 3.13 & 7.22 & 2.41 & -0.17 \\
7th & -0.63 & 2.95 & 13.44 & 2.52 & -0.20 \\
8th & -0.63 & 2.95 & 11.49 & 2.41 & -0.21 \\
9th & -0.57 & 2.92 & 35.55 & 2.68 & -0.18 \\
10th & -0.65 & 2.83 & 21.67 & 2.80 & -0.24 \\
\hline
\end{tabular}

Source: A3E-G model projections, 1st-10th range poorest to richest.

of luxury commodities because when using a proper revenue recycling policy, household consumption patterns can be effectively changed to switch towards consumption of more efficient energy saving luxury commodities.

The percentage change in utility is progressive under a CTX policy and all the revenue recycling policies improve the utility levels of households in varying ways. For example, under the LSO policy, utility levels have improved towards lower income groups whereas under the LSE policy utility levels have improved towards higher income groups. This is mainly because the carbon tax has mildly progressive impacts on the economy and middle and higher income groups will be better off as they receive an equal amount of compensation. This is also shown in Table 7 in terms of the percentage change in utility when measured in actual dollar values, all revenue recycling policies generate significant welfare improvement towards higher income household groups. As shown the welfare is much higher when carbon revenue is used

Table 7. EV as a percentage change in post tax income.

\begin{tabular}{lccccr}
\hline Household income deciles & CTX & LSO & LSE & INC & GST \\
\hline 1st & -0.002 & 0.262 & 0.152 & 0.115 & 0.002 \\
2nd & -0.001 & 0.457 & 0.167 & 0.233 & 0.007 \\
3rd & -0.025 & 0.436 & 0.276 & 0.302 & 0.007 \\
4th & -0.043 & 0.548 & 0.292 & 0.346 & -0.006 \\
5th & -0.086 & 0.447 & 1.196 & 0.351 & -0.023 \\
6th & -0.103 & 0.549 & 1.266 & 0.423 & -0.029 \\
7th & -0.130 & 0.606 & 2.757 & 0.517 & -0.041 \\
8th & -0.147 & 0.688 & 2.684 & 0.562 & -0.050 \\
9th & -0.160 & 0.820 & 9.977 & 0.753 & -0.052 \\
10th & -0.260 & 1.123 & 8.602 & 1.112 & -0.094 \\
\hline
\end{tabular}

Source: A3E-G model projections, 1st-10th range poorest to richest. 
for lump-sum transfers. This mainly occurs when the government transfers income from relatively higher income households to relatively lower income households, the higher income households tend to save less and increase their consumption. Thus, there is an overall improvement in welfare in the short-run.

The monetary measure of the welfare effects of the price rise is termed as the EV. $\mathrm{EV}$ indicates the maximum amount that the consumer would be willing to pay to avoid a price change. From Table 7, it is apparent that high income households suffer more compared to low income households in monetary terms under the CTX scenario. However, when welfare is measured as EV, compensation has clearly improved the welfare of higher income groups compared to lower income groups. This empirical study suggests that the carbon tax in Australia is not necessarily regressive but in fact, the actual impacts of carbon tax are mildly progressive. As such economic efficiency improves if the carbon tax is recycled through income tax reduction (INC) or equallump sum transfers (LSE).

\section{Sensitivity Analysis}

Simulation results obtained from the A3E-G model often rely on values assigned for key exogenous parameters. There is a large number of elasticity parameters introduced into the model equations and these values were obtained from the ORANI-G database, other literature and from the authors' own judgements. Since parameter values play a crucial role in the accuracy of the model results, it is important to find out how variations in the values of these parameters affect the model results. This is addressed by implementing a sensitivity test for the parameter values used in this study. A systematic sensitivity analysis (SSA) was performed via a Gaussian Quadrature which is a type of optimization method. With the given distribution of $M$ exogenous variables (parameters), Gaussian Quadrature estimates means and standard deviations of all endogenous variables by choosing the best possible $N$ simulations. In performing the SSA, all parameters were assumed to have triangular distributions. The optimum number of simulations was then determined using the Stroud Quadrature.

Table 8 reports the mean, standard deviation and confidence interval of the selected variables under the SSA carried out for CTX scenario. All parameters were varied by $50 \%$ from their mean values to check the sensitivity of the results. Overall, the results reveal that the percentage change in endogenous variables is fairly robust or insensitive to a variation in parameters (exogenously determined). Furthermore, SSA mean values are not significantly different to the original simulation results. Because the standard deviations from the mean values among many endogenous macro variables are considerably low, it can be concluded with $95 \%$ confidence that the results are generally robust with respect to a $50 \%$ parameter variation. For example, there is a $95 \%$ confidence that real GDP, aggregate real consumption, aggregate employment and exports will fall and the consumer price index will rise with a $\mathrm{A} \$ 23$ carbon price. However, in the case of imports, because the upper confidence interval is non-negative, it cannot be 
Table 8 . SSA of $50 \%$ variation in all parameters.

\begin{tabular}{|c|c|c|c|c|}
\hline \multirow[t]{2}{*}{ Variable (percentage change) } & \multirow[t]{2}{*}{ Mean } & \multirow[t]{2}{*}{ Standard dev } & \multicolumn{2}{|c|}{ Confidence interval (95\%) } \\
\hline & & & Lower & Upper \\
\hline Real GDP & -0.601 & 0.067 & -0.900 & -0.301 \\
\hline Aggregate consumption & -0.170 & 0.013 & -0.228 & -0.112 \\
\hline Consumer price index & 0.704 & 0.093 & 0.228 & 1.120 \\
\hline Aggregate employment & -0.875 & 0.083 & -1.246 & -0.504 \\
\hline Import volume & 0.062 & 0.089 & -0.336 & 0.460 \\
\hline Export volume & -2.739 & 0.345 & -4.281 & -1.197 \\
\hline Emissions reduction & -11.947 & 0.804 & -15.541 & -8.335 \\
\hline \multicolumn{5}{|c|}{ Household consumption by deciles } \\
\hline 1st decile & -0.002 & 0.002 & -0.013 & 0.009 \\
\hline 2nd decile & -0.001 & 0.003 & -0.014 & 0.016 \\
\hline 3rd decile & -0.030 & 0.005 & -0.050 & -0.010 \\
\hline 4th decile & -0.051 & 0.006 & -0.079 & -0.023 \\
\hline 5th decile & -0.107 & 0.008 & -0.143 & -0.071 \\
\hline 6th decile & -0.128 & 0.010 & -0.172 & -0.084 \\
\hline 7th decile & -0.162 & 0.012 & -0.215 & -0.109 \\
\hline 8th decile & -0.186 & 0.014 & -0.246 & -0.126 \\
\hline 9th decile & -0.211 & 0.017 & -0.286 & -0.136 \\
\hline 10th decile & -0.328 & 0.021 & -0.423 & -0.233 \\
\hline
\end{tabular}

Source: A3E-G model projections.

concluded with $95 \%$ confidence that imports will fall following a carbon price. The emissions reduction is also robust with respect to parameter variation even though the standard deviation is wide.

\section{Conclusion, Policy Implications and Suggestions for Further Research}

Household level impacts range from a proportional to a mildly progressive tax incidence in the short-run. This is due mainly to the 'sources' side of the household account, that is, to household income changes resulting from the carbon price. Households receiving a larger proportion of their income through wages are affected quite significantly in the short-run. However, household impacts become less significant when households receive a larger portion of their income through government transfers. Furthermore, the results reveal that low income households can be more vulnerable to carbon price with respect to changes in patterns of energy consumption.

The macroeconomic impacts and household distributional results with respect to income, utility and EV were compared with CTX policy. Our key findings lead to the following conclusions and policy implications: firstly, all revenue recycling policies have almost the same emissions reductions as the CTX policy. This effect can be seen as a positive aspect of the revenue recycling as there will be no additional burden on the environment. On the other hand, economic efficiency improves under all revenue 
recycling policies with a $60 \%$ gain in the real GDP under the LSE and GST policies compared to the CTX policy. The other two options - LSO and INC policies lessen the real GDP fall slightly as compared to the CTX policy real GDP fall. The aggregate household real consumption has also increased under all revenue recycling policies compared to the CTX policy with varying magnitudes. The highest increase in real consumption, a 5.26\% increment is observed under the LSE policy. With respect to consumer price index changes, the GST reduction policy has changed the CPI by $-0.25 \%$. As a result, exports have expanded by $54 \%$ compared to the CTX policy. From the macroeconomic point of view, the LSE policy brings severe negative impacts on exports. This suggests that policy makers should consider the welfare implications of both the consumer and the producer when deciding the type of revenue recycling policy.

Secondly, household real incomes have improved under all compensation policies compared to the CTX policy. The compensation via LSO is favorable towards low income households whereas LSE is favorable towards middle income and high income groups. Furthermore, the LSO policy has been found to be more favorable in uplifting the post tax income of deciles 1 to 4 and the LSE policy has made significant progress of the post tax income levels of deciles 5 to 10 . Therefore, both lump-sum transfer options can be recommended to improve the real income of households in Australia. The choice of the two policies determines which income group needs compensation. The INC policy has given positive income changes for the deciles 2, 3 and 10 . However, the overall impacts of the INC policy on household post tax income shows significant increase in income levels of households. The GST policy has been found to be less effective in improving post tax income levels of the households although there is some improvement compared to the CTX policy.

Thirdly, changes in household utility under various recycling policies were compared with the CTX policy because household utility can be used as a good indicator of welfare. It was observed that the household utility change is progressive under the CTX policy. The revenue recycling with the LSO policy improves the utility further towards low income households, whereas the LSE policy improves utility towards middle and high income households. The INC policy has proportionately improved household utility. There was no significant effect from the GST policy on household welfare.

Finally, all the compensation options have significantly improved household EV towards high income groups. The EV indicates the maximum amount that the consumer would be willing to pay to avoid a price change. Because high and middle income groups were relatively more severely affected in monetary terms under a carbon tax policy, it was obvious that these groups may benefit most from the compensation.

Overall, the results of this study suggest the fairly surprising outcome that the distributive impacts of Australia's carbon tax might have been mildly progressive, although, it appears that politics - and in particular a view that the carbon tax was unfair to low income households has prevailed over objective assessment of impacts. 
The study suggests the ways carbon tax revenue could have been used to mitigate such impacts, if neutrality is a policy objective. The lump-sum transfer options are not the best options to maximize the efficiency gains from the tax, but are probably the mostly politically appealing. Finally, as lessons for countries now considering a tax, the study underlines the usefulness of undertaking thorough general equilibrium studies of the impacts of the tax and compensation options.

\section{Acknowledgment}

The authors would like to acknowledge funding from the Australian Research Council under Discovery project DP0986306.

\section{References}

ABARE (1996). The MEGABARE model: Interim documentation, Commonwealth of Australia, Canberra.

-Adams, PD (2007). Insurance against catastrophic climate change: How much will an emissions trading scheme cost Australia? Australian Economic Review, 40(4), 432-52.

Adams, P and PB Dixon (1992). Disaggregating oil, gas and brown coal. Mimeo, Centre of Policy Studies, Monash University, Melbourne.

Adams, P, B Parmenter and J Horridge (2000a). MMRF-GREEN: A dynamic, multi-sectoral multi-regional model of Australia. Centre Working Papers, Op-94, Centre of Policy Studies/ IMPACT Project, Monash University, Melbourne.

Adams, P, B Parmenter and J Horridge (2000b). Analysis of greenhouse policy using MMRFGreen. Centre Working Papers, Centre of Policy Studies, Monash University, Melbourne.

Australian Government (2008). Australia's Low Pollution Future: The Economics of Climate Change Mitigation. Canberra: Commonwealth of Australia.

Australian Government (2011a). Strong Growth, Low Pollution: Modelling a Carbon Price. Canberra: Commonwealth of Australia.

Australian Government (2011b). Strong Growth, Low Pollution: Modelling a Carbon Price Update. Canberra: Commonwealth of Australia.

Australian Government (2011c). Clean Energy Act 2011. An Act to encourage the use of clean energy, and for other purposes, ComLaw Authoritative Act, C2011A00131, Available at http://wwwcomlaw/gov/au/.

Baumal, WJ and EW Oates (1988). The Theory of Environmental Policy, 2nd edition. Cambridge: Cambridge University Press.

Baranzini, A (1997). International economic instruments and global warming mitigaiton: An analysis of their acceptability. Working Paper W54, International Academy of Geneva.

-Barker, T, S Baylis and P Madsen (1993). A UK carbon/energy tax: The macroeconomic effects. Energy Policy, 21(3), 296-308.

-Bor, YJ and Y Huang (2010). Energy taxation and the double dividend effect in Taiwan's energy conservation policy - An empirical study using a computable general equilibrium model. Energy Policy, 38, 2086-2100.

Bosello, F, C Carraro and M Galeotti (2001). The double dividend issue: Modeling strategies and empirical findings. Environmental and Development Economics, 6, 9-45.

-Bovenberg, L (1995). Environmental taxation and employment. De Economist, 143, 111-140. 
Bovenberg, L and L Goulder (1998). Enviornmental taxation and the double divident. Emprica, 25, 15-135.

Bovenberg, L and L Goulder (1999). Green tax reforms and the double dividend: An updated reader's guide. Economic Journal, 104, 444-454.

Carbone, JC, RD Morgenstern, RC Williams and D Burtraw (2013). Deficit reduction and carbon taxes: Budgetary, economic and distributional impacts. Avaialable at http://www.rff. org/RFF/Documents/RFF-Rpt-Carbone.etal.CarbonTaxes.pdf (accessed on August 2013).

Devarajan, S, DS Go, S Robinson and K Thierfelder (2009). Tax policy to reduce carbon emissions in South Africa. Policy Research Working Paper, 4933 (May).

Devarajan, S, DS Go, S Robinson and K Thierfelder (2009). Tax policy to reduce carbon emissions in a distorted economy: Illustrations from a South Africa CGE model. The B.E. Journal of Economic Analysis and Policy, 11(1), 1-22.

-Dinan, TM and DL Rogers (2002). Distributional effects of carbon allowance trading: How government decision determine winners and loosers. National Tax Journal, 55(2), 199-221.

Dixon, PB, BR Parmenter, GJ Ryland and JM Sutton (1977). ORANI, A General Equilibrium Model of the Australian Economy: Current Specification and Illustrations of Use for Policy Analysis, First Progress Report of the IMPACT Project, Vol. 2. Canberra: Australian Government Publishing Services.

Dixon, PB, BR Parmenter, J Sutton and D Vincent (1982). ORANI: A Multisectoral Model of the Australian Economy. Amsterdams: North-Holland.

Garnaut, R (2008). The Garnaut Climate Change Review, Final Report. Cambridge: Cambridge University Press.

-Hamilton, K and G Cameron (1994). Simulating the distributional effects of a Canadian carbon tax. Canadian Public Policy, 20(4), 385-399.

Hertal, TW (1997). Global Trade Analysis: Modeling and Applications. New York and Melbourn, Cambridge University Press.

Horridge, JM (2000). ORANI-G: A General equilibrium model of the Australian economy. IMPACT Centre Working Papers, op-93, Centre of Policy Studies, Monash University.

-Klein, LR and H Rubin (1948-49). A constant utility index of the cost of living. Review of Economic Studies, 15, 84-87.

Labandeira, X, JM Labeaga and M Rodriguez (2004). Green tax reforms in Spain. European Environment, 14, 290-299.

Labandeira, X, JM Labeaga and M Rodriguez (2009). An integrated economic and distributional analysis of energy policies. Energy Policy, 37, 5776-5786.

-Lee, D and W Misiolek (1986). Substituting pollution taxation for general taxation: Some implications for efficiency in pollution taxation. Journal of Environmental Economics and Management, 13, 338-347.

Marron, D and E Toder (2013). Carbon taxes and corporate tax reform. Tax Policy Centre Working Paper, Avaialable at http://www.taxpolicycentre.org/UploadedPDF/412744Carbon-Taxes-and-Corporate-Tax-Reform.pdf.

-Mathur, A and A Morris (2014). Distributional effects of a carbon tax in broader U.S. fiscal reform. Energy Policy, 66, 326-334.

McDougall, RA (1993a). Short-run effects of a carbon tax. General paper, No. G-100, Centre of Policy Studies, Monash University.

McDougall, RA (1993b). Energy taxes and greenhouse gas emissions in Australia. General paper, No. G-104, Centre of Policy Studies, Monash Univeristy.

-McKitrick, R (1997). Double dividend enviornmental taxation and Canadian carbon emissions control. Canadian Public Policy, 23(4), 417-434. 
Metcalf, GE (2007). A green employment tax swap: Using a carbon tax to finance payroll tax relief. The Brooking Institution, Avaialable at http://www.taxpolicycentre.org/UploadedPDF/412744-Carbon-Taxes-and-Corporate-Tax-Reform.pdfGreenTaxSwap.pdf.

Metcalf, GE (2013). Using the tax system to address competition issues with a carbon tax. The Resources for the Future's Centre for Climate Change and Electricity Policy, RFF Discussion paper, 13-30.

-Oladosu, G and A Rose (2007). Income distribution impacts of climate change mitigation policy in the Susquehanna river basin economy. Energy Economics, 29(1), 520-544.

Parry, IW (1997). Revenue recycling and the costs of reducing carbon emissions. Climate Issues Brief, No. 2. Resources for the Future, Washington, DC.

Powel, AA and RH Snape (1993). The contribution of applied general equilibrium analysis to policy reform in Australia. Working Paper no G-98, Centre of Policy Studies, IMPACT Centre.

Pigou, C (1932). The Economics of Welfare. London: Macmillan and Co. Ltd.

Rausch, S, GE Metcalf, JM Reilly and S Paltsev (2010). U.S. energy tax policy. In Distributional Impacts of a U.S. Greenhouse Gas Policy: A General Equilibrium Analysis of Carbon Pricing. MA: Cambridge University Press, 52-107.

Round, J (2003). Constructing SAMs for development policy analysis: Lessons learned and challenges ahead. Economic Systems Research, 15, 161-183.

-Schob, R (1997). Environmental taxes and pre-existing distortion: The normalization trap. International Tax and Public Finance, 4, 167-176.

Standaert, S (1992). The macro-sectoral effects of an EC-wide energy tax. In An Energy Tax in Europe, F Laroui, and JW Velthuijsen (eds.), SEO Report, No. 281, Amsterdam, 1997-240.

-Telli, C, E Voyvoda and E Yeldan (2008). Economics of environmental policy in Turkey: A general equilibrium investigation of the economic evaluation of sectoral emission reduction policies of climate change. Journal of Policy Modeling, 30, 321-340.

Tullock, G (1967). Excess benifit. Water Resources Research, 3, 643-644.

Yusuf, AA and BP Resosudarmo (2007). On the distributional effect of carbon tax in developing countries: The case of Indonesia. Working Paper in Economics and Development Studies, 200605, Department of Economics, Padjadjaran Universtiy.

Zhang, ZX and A Baranzini (2004). What do we know about carbon taxes? An inquiry into their impacts on competitiveness and distribution of income. Energy Policy, 32, 507-518. 